\title{
A distopia brasileira: o governo dos homens baixos
}

Distopía brasileña: el gobierno de los hombres de baja estatura moral

La dystopie brésilienne: le gouvernement des hommes vils

Brazilian dystopia: under the government of immoral men

\section{Glauco Bruce Rodrigues}

\section{(2)enEdition}

Journals

\section{Edição electrónica}

URL: http://journals.openedition.org/espacoeconomia/12871

DOI: 10.4000/espacoeconomia.12871

ISSN: 2317-7837

\section{Editora}

Núcleo de Pesquisa Espaço \& Economia

\section{Refêrencia eletrónica}

Glauco Bruce Rodrigues, "A distopia brasileira: o governo dos homens baixos », Espaço e Economia [Online], 18 | 2020, posto online no dia 20 abril 2020, consultado o 20 maio 2020. URL : http:// journals.openedition.org/espacoeconomia/12871; DOI : https://doi.org/10.4000/espacoeconomia. 12871

Este documento foi criado de forma automática no dia 20 maio 2020.

(C) NUPEE 


\title{
A distopia brasileira: o governo dos homens baixos
}

\author{
Distopía brasileña: el gobierno de los hombres de baja estatura moral \\ La dystopie brésilienne: le gouvernement des hommes vils \\ Brazilian dystopia: under the government of immoral men
}

Glauco Bruce Rodrigues

1 A distopia nos remete a uma realidade marcada por tragédias, tristezas, violência, crueldade, controle, desespero e, no limite, uma realidade sem esperança ${ }^{1}$. A arte, nas suas diferentes formas, produziu diversas realidades distópicas que, para além do entretenimento, nos levam a refletir sobre o conteúdo concreto das relações sociais, afetos, projetos e devires das sociedades. As diferentes obras nos apresentam mundos distópicos caracterizados por regimes totalitários, como o clássico 1984, de George Orwell, ou mundos pós-apocalípticos, como Mad Max e A Madrugada dos Mortos. Exemplos não faltam. O que há em comum entre eles é uma vida que está sempre por um fio, sempre sendo espreitada pela morte, pela doença, pela violência, pela crueldade. Não há descanso, não há pausa, não há pôr do sol, cheiro de chuva. Só há a espera, a luta, a fuga. E, ainda assim, a vida se afirma.

2 O Brasil contemporâneo vive sua distopia. De junho de 2013 em diante, diversos processos e eventos que julgávamos impossíveis (digo impossíveis e não improváveis) se transformaram em realidade. Não esperávamos milhões de pessoas nas ruas em junho. Não esperávamos o crescimento tão rápido e violento de uma extrema-direita. Não esperávamos que o projeto de contenção do caos social engendrado pelo Partido dos Trabalhadores fosse ruir em apenas três anos. Por fim, não esperávamos que em 2018 fosse eleito um candidato cujo ídolo foi um monstro que levava crianças para assistirem seus pais serem torturados.

3 A partir de 2016, o Brasil foi tomado pelo que denominamos o governo dos homens baixos. Esse governo dos homens baixos é que caracteriza a distopia brasileira. o que são os homens baixos? São aqueles movidos por todo tipo de paixão triste e pulsão de morte. 0 tipo de projeto de sociedade é baseado na força, na intolerância, na violência, 
na desigualdade, na crueldade. Distopia social que joga todos contra todos, criando um Estado misto de teocracia evangélica com darwinismo social e austericídio neoliberal. Uma distopia social que entende segurança como morte e encarceramento do outro, principalmente se for negro e pobre, que vê a natureza e sociedades tradicionais e originárias como um inimigo a ser destruído, que vê a mulher como submissa e servil ao homem, que vê homossexuais, transgêneros, bissexuais e as demais formas de viver a sexualidade e o gênero como aberrações. Uma distopia social fundamentada, de forma ainda mais violenta, na exploração do trabalho e na sacralização da propriedade privada. Uma distopia que é inimiga da Educação e da Ciência, que vê em Paulo Freire um inimigo a ser combatido, ao mesmo tempo em que terraplanistas e astrólogos animam uma multidão de pessoas que não acreditam na eficácia das vacinas e tem certeza da existência de uma conspiração comunista global, que envolve o Partido Comunista Chinês e George Soros.

4 Os homens desse tipo explicitam toda sua baixeza no debate público. Sua postura, sua fala, suas ações demonstram a ausência de qualquer traço de educação, urbanidade, civilidade e equilíbrio. As falas e gestos sempre são carregadas de violência, escárnio, desprezo e ameaças ao outro. A infâmia, a ignorância e o destempero das reações são os principais traços das manifestações públicas dos homens baixos. Eles consideram sua ignorância, sua infâmia como virtudes: julgam que tais atributos exprimem a coragem, a masculinidade, a espontaneidade e, por fim, os fazem crer que assim tornam-se iguais aos homens e mulheres do povo. Quantas vezes não ouvimos que o atual presidente é "verdadeiro, fala o que pensa, não tem medo dos poderosos"? Os atributos da baixeza, para eles, são os fundamentos de uma nova ordem societária.

5 Não bastasse o governo dos homens baixos, um novo e icônico elemento das realidades distópicas é acrescentado à realidade brasileira: um vírus.

6 A partir de fevereiro de 2020 somos colocados diante de mais um evento que jamais foi sequer imaginado por nós: vivenciar uma quarentena forçada em função de uma pandemia global. Um parêntesis. Vamos usar o termo quarentena de forma livre, sem uma precisão técnica para nos referir, de forma ampla, a um processo necessário de isolamento social dos corpos em função do risco de contaminação e disseminação de uma doença que possui poucos meses de existência.

7 Assim como outros eventos, não imaginávamos vivenciar tal experiência. No entanto, como nos lembra Marx, os homens não fazem História nas condições determinadas ou escolhidas por eles. A questão fundamental é: como vamos passar por essa experiência? Que lições poderemos tirar para reconstruir, minimamente, uma utopia que nos permita agir, aqui e agora, contra a distopia do real que se abateu no Brasil a partir do dia 28 de outubro de $2018^{2}$ ?

8 A disseminação rápida do vírus obrigou que a Organização Mundial da Saúde criasse um protocolo rigoroso para se controlar a epidemia: testagem do maior número de pessoas possíveis, identificação das pessoas contaminadas, isolamento (quarentena no sentido técnico preciso), tratamento das pessoas e, finalmente, a redução, ao máximo da circulação das pessoas. $O$ objetivo do protocolo é não sobrecarregar os sistemas de saúde com um número muito elevado de pessoas com a necessidade de atendimento médico. A preocupação fundamental é a escassez de leitos com os equipamentos e materiais hospitalares e de proteção necessários.

9 A testagem do maior número possível de pessoas não foi possível em diversos países, pelos mais diversos motivos. Para se evitar o colapso do sistema de saúde era necessário 
reduzir o contato entre as pessoas, o que implica deixá-las em casa. Aqui, a resposta foi muito variada. Os países com maior êxito em evitar o avanço da pandemia (Coréia do Sul, Alemanha) adotaram medidas rígidas de isolamento social, fechando o comércio, escolas, shoppings, fábricas, proibindo a circulação de pessoas na rua sem uma boa justificativa. Foram mantidos apenas os serviços essenciais (luz, água, energia, internet, segurança, saúde, mercados, farmácias, etc.). Outros países hesitaram em tomar tais medidas e menosprezaram tanto a capacidade de disseminação como a mortalidade do vírus. Talvez o exemplo mais dramático seja a Itália. o prefeito de Milão, no início da pandemia, lançou uma campanha contra o isolamento e manteve o comércio aberto. Aproximadamente quinze dias depois o número de mortos fez com que ele fizesse um pronunciamento se arrependendo amargamente da decisão. Hoje, a Itália adota medidas rígidas de isolamento, assim como a França e a Espanha. Vieram da Itália várias cenas que nos causaram profunda tristeza e comoção. Uma coluna de caminhões do exército levando caixões de uma cidade para outra, sem que os familiares pudessem se despedir de seus entes queridos, uma igreja com vários caixões enfileirados para que o padre pudesse fazer uma rápida oração coletiva e, finalmente, a cena do Papa Francisco, caminhando sozinho na Praça São Pedro, no Vaticano, em um início de noite chuvoso, para iniciar a benção do Urbi et Orbi. Não é necessário ser católico ou religioso para não se comover com a figura do Papa frágil, caminhando com auxílio de um padre, em uma das praças mais movimentadas do mundo, agora completamente silenciada.

10 Na distopia do Império, o presidente Donald Trump desdenhou da necessidade do isolamento. Ainda assim, não deixou de agir no plano econômico: Trump sancionou o maior pacote de estímulo econômico da história, orçado em nada mais nada menos do que 2 trilhões de dólares, para se combater a crise social e econômica causada pela pandemia. Trump, assim como os demais capitalistas, está mais preocupado com a economia do que com a população, no entanto, teve que adotar a medida mais óbvia: a intervenção do Estado para preservar a renda e os empregos da classe trabalhadora. É certo que a maior parte dos recursos será utilizada para salvar as grandes corporações (algo em torno de 500 bilhões de dólares), no entanto, não é desprezível o esforço econômico que está sendo adotado. No entanto, agora, no momento em que escrevemos, dia 29 de março, os EUA já se tornaram o novo epicentro da pandemia, com

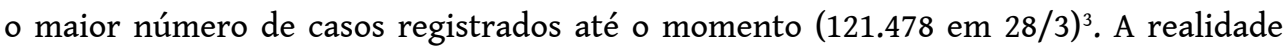
obrigou o presidente, que até então era contra medidas de isolamento, a implementálas até o dia 30 de abril. Como no Brasil, os protagonistas da gestão da crise eram governadores e prefeitos. Trump afirmou que gostaria de ver o país retomando as atividades econômicas até a Páscoa, o que não vai acontecer. Lá, ao menos, o presidente ouviu a razão.

11 Ao redor do mundo, diversas medidas tem sido tomadas para tentar proteger, minimamente, a classe trabalhadora dos efeitos do Covid-19: proibição de despejo por falta de pagamento de aluguel, pagamento de salários por parte do Estado, estabelecimento de renda mínima, suspensão do pagamento de contas de energia, água e gás, linhas especiais de crédito para empresas que não demitirem trabalhadores, linhas de financiamento para as empresas, entre outras.

12 No Brasil, assistimos o comportamento baixo e vil do Presidente da República e sua absoluta incompetência para lidar com a crise. O governo de extrema-direita da distopia brasileira, até agora, só demonstrou alguma preocupação com a economia, ou melhor, com a classe dos capitalistas. A grande preocupação do Ministro da Economia é 
evitar o aumento dos gastos públicos. Repete-se isso como um mantra infinito, um disco arranhado. Grande parte da imprensa burguesa e liberal já aceitou o fato de que o Estado é fundamental para lidar com a crise e que a ampliação robusta dos gastos públicos é uma necessidade (evidentemente que a imprensa burguesa defende que tais gastos sejam apenas para superar a crise, uma vez debelada pode-se retornar com a política austericida). No entanto, a realidade se impõe e o Governo Federal se vê obrigado a agir. O ministro do STF, Alexandre de Moraes, atendendo a um pedido da Advocacia Geral da União, permitiu a flexibilização da Lei de Responsabilidade Fiscal e a Lei de Diretrizes Orçamentárias para enfrentar a crise, estendendo sua decisão para estados e municípios que decretarem estado de calamidade. Voltemos ao Presidente da República.

13 O discurso baixo e vil do ocupante do Palácio do Planalto vai de encontro a todas as recomendações da Organização Mundial da Saúde, contra todos os especialistas no assunto, contra as diretrizes do seu próprio Ministro da Saúde, que todo dia se vê obrigado a confrontar, direta ou indiretamente, os discursos, falas e pronunciamentos irresponsáveis de seu superior.

14 O desejo do Presidente da República é acabar com as medidas de isolamento social adotadas por prefeitos e governadores. Um parêntesis: se não fossem eles, mesmo aqueles alinhados ao espírito da extrema-direita que assolou o Brasil, estaríamos vivendo um verdadeiro caos; são prefeitos e governadores, de forma geral, que tomaram as medidas necessárias e corretas para se reduzir a velocidade do contágio e, com isso, reduzir o colapso no sistema de saúde e, consequentemente, salvando vidas.

15 No seu pronunciamento em cadeia nacional, no dia 24 de março assistimos, estarrecidos, o ponto mais baixo e vil do comportamento do Presidente da República. Talvez ainda mais baixo e vil do que no momento em que homenageia o torturador Carlos Alberto Brilhante Ustra no seu voto durante o impeachment da presidenta Dilma Rousseff. Temos ali, de forma cristalina, todo o conteúdo da extrema-direita, cuidadosamente planejado para inflamar sua base de apoio. Não se trata, obviamente, de pura ignorância, mas de estratégia política: o pronunciamento é um chamado à luta. Está tudo lá: a crítica à imprensa, segundo ele, culpada por gerar um clima de histeria; os empregos devem ser preservados, mas não por uma ação governamental, mas pela volta dos trabalhadores às suas atividades; o clamor pela volta à normalidade; a crítica aos governadores e prefeitos que instituíram medidas de isolamento; não aceita o fechamento de escola, afirma que o grupo de risco se restringe à pessoas com mais de 60 anos; justifica seu posicionamento em função do índice relativamente baixo de mortalidade do vírus; de forma zombeteira e infame, afirma que caso venha a contrair o vírus, não sentiria nada em função do seu "histórico de atleta" e, no máximo, "seria acometido por um resfriadinho ou uma gripezinha".

16 Não satisfeito com seu pronunciamento do dia 24 , o presidente, no fim de semana, contrariando todas as recomendações, resolveu dar um passeio ${ }^{4}$, causando pequenas aglomerações e tendo contato com outras pessoas. Após o passeio, em uma entrevista para a imprensa, suas declarações mantiverem a baixeza de sempre. Afirmou, por exemplo, que estava pensando em baixar um decreto liberando, completamente, a volta ao trabalho, acabando com o isolamento social ${ }^{5}$. A quarentena seria apenas para as pessoas do grupo de risco (idosos e pessoas com doenças pré-existentes). Fez afirmações do tipo "o vírus tá aí e temos que enfrentá-lo, mas enfrentar como homem e não como moleque", "é a vida... todos nós iremos morrer um dia", "vai condenar esse 
cara a ficar dentro de casa? Ele não tem poupança, não tem renda, a geladeira, se tiver, já acabou a comida, ele tem que trabalhar, tem que sustentar sua família, cuidar dos seus filhos", "tem mulher apanhando em casa, por que isso? Em casa que falta pão, ninguém tem razão... como é que acaba isso? Tem que trabalhar, meu Deus do céu! É crime trabalhar?".

17 O comportamento baixo e vil expressa o conteúdo da luta de classes no Brasil da distopia contemporânea. Após seu pronunciamento do dia 24, foram convocadas diversas carreatas pelo Brasil reivindicando o fim do isolamento e pela volta ao trabalho. As carreatas não ocorreram em qualquer lugar. Ocorreram em áreas centrais ou ricas das cidades. $O$ lugar da ação pode nos ajudar a compreender seu conteúdo. Nos lugares centrais das cidades, ocupados pelos automóveis das elites e classes médias, empresários, comerciantes, protegidos dentro de seus carros, pediam a volta ao trabalho, alegando, principalmente, que eles não poderiam manter os empregos sem atividade econômica e que eles também tinham família para sustentar. Podíamos ler adesivos com a seguinte frase: "nós pagamos o seu salário". Grandes empresários se manifestaram em redes sociais afirmando que o caos econômico causado pelo isolamento seria muito pior do que as mortes causadas pelo vírus. Alguns deveriam se sacrificar pelo bem da maioria. Claro, o sacrifício sempre recai sobre o trabalhador. A solução é sempre pelo retorno à exploração. Não se coloca no horizonte do governo dos homens baixos taxar grandes fortunas, dividendos e usar recursos públicos para garantir emprego e renda dos trabalhadores durante o isolamento. Não poderíamos estar pensando em expropriações de grandes riquezas?

18 Curioso notar que esta expressão concreta da luta de classes deixa explícita a ideia segundo a qual quem produz a riqueza social é o trabalhador. 0 mito contemporâneo do empreendedor, do empresário que gera empregos e é o responsável pela produção da riqueza simplesmente se desmancha no ar a partir do momento em que o pânico toma conta dessa entidade quase mística denominada mercado, quando a força de trabalho não pode mais ser explorada e, consequentemente, gerar valor. A paralisação do processo de produção de mais-valia e, consequentemente, do processo de acumulação é a causa do pânico dos grandes capitalistas e seus capatazes (a classe média remediada, a pequena burguesia e afins). Nesse momento, é absolutamente necessário explicitar a potência da classe trabalhadora, sua centralidade econômica e política, sua capacidade de ação e de autogestão, na perspectiva de uma politização da sociedade visando a construção de um projeto diferente, que possa enfrentar a nossa atual distopia.

19 Assim, as manifestações pela volta ao trabalho não estão fundamentadas em nenhuma solidariedade de classes, mas pela necessidade da retomada do processo de exploração. No entanto, o discurso que defende a reabertura do comércio, a retomada das atividades econômicas e o relaxamento das medidas de isolamento tem um objetivo prático: esse discurso busca ganhar o apoio das classes populares, pois coloca a quarentena como uma possibilidade de escolha apenas para os ricos, funcionários públicos e políticos. Os trabalhadores, por outro lado, não teriam a possibilidade de se proteger em função das necessidades imediatas. Assim, um quadro de desigualdade estrutural é utilizado pelo governo dos homens baixos para tentar conquistar apoio popular ao se colocar ao lado do povo. No entanto, a solução proposta perpetua tal desigualdade. A quarentena não deve ser encarada como um privilégio, mas sim como um direito que está sendo roubado dos trabalhadores, uma vez que o Estado não está 
criando as condições para que a população tenha seus empregos e sua renda minimanete preservados e não seja obrigada a escolher entre sua saúde e o emprego.

20 No início da crise o governo dos homens baixos acenou com a possibilidade de se criar um auxílio a desempregados e trabalhadores informais de $\mathrm{R} \$ 200,00$. A iniciativa não foi adiante. Coube ao Congresso Nacional, com o protagonismo de parlamentares da oposição, formular um projeto de auxílio para trabalhadores informais e desempregados que podem variar de $\mathrm{R} \$ 600,00$ a 1.200,00 por família e deverá mobilizar, aproximadamente, $\mathrm{R} \$ 98$ bilhões. O projeto foi aprovado na Câmara e no Senado (aqui, a aprovação foi realizada no dia 30 de março). A medida, apesar de seu caráter absolutamente emergencial, foi sancionada pelo presidente no dia 2 de abril. Tal medida ainda gerou preocupações no Ministro da Economia, que afirmou que "não sabe de onde vai tirar esse dinheiro"6 e que ainda falta segurança jurídica para dispor de tais recursos, o que foi imediatamente desmentido pelo Presidente da Câmara dos Deputados$^{7}$. Também não nos causa nenhuma surpresa a posição do Governo em relação ao prazo para o início dos pagamentos após a sanção presidencial: 16 de abril. A alegação para a demora é a "complexidade de organizar os pagamentos", segundo o Ministro da Cidadania ${ }^{8}$. O sentido de emergência para o governo dos homens baixos é outro. Considerando os cadastros dos beneficiários do Bolsa Família e do Cadastro Único, existe uma base de dados e de infraestrutura técnica que permite antecipar em muitos dias o início dos pagamentos. No entanto, a urgência em dispor de recursos públicos para os trabalhadores não é tão urgente (muito menos desejada) quanto permitir a volta ao trabalho. Apesar da sanção presidencial, o Governo alega a necessidade de edições de decretos e medidas provisórias para a liberação do crédito, o que ainda não foi feito.

21 Em relação à manutenção dos empregos e da renda dos trabalhadores formais, o Planalto anunciou a Medida Provisória 935/209, que destina R\$ 51 bilhões para o Programa Emergencial de Manutenção do Emprego e da Renda, instituído pela Medida Provisória $936 / 20^{10}$, que regulamenta a forma como os trabalhadores serão ajudados. Em linhas gerais, a MP permite que o contrato de trabalho seja suspenso ou que ocorram reduções de $25 \%, 50 \%$ e $70 \%$ da jornada de trabalho com a respectiva redução do salário. A compensação para o trabalhador seria calculada em relação ao valor do seguro-desemprego a que teria direito em caso de demissão (o valor atual do segurodesemprego varia entre $\mathrm{R} \$ 1.045$ e $\mathrm{R} \$ 1.813,03$ ), além disso, esse valor não contaria para o cálculo de contribuição previdenciária, férias, 13ํㅗa sário, ou FGTS. Pela MP, nenhum trabalhador ganhará menos do que um salário mínimo. Pelas simulações ${ }^{11}$ feitas por economistas, a perda salarial será maior para quem ganha mais ${ }^{12}$, particularmente a partir de salários de $\mathrm{R} \$ 4$ mil. Especialistas já chamam a atenção para certos pontos inconstitucionais da MP, como a possibilidade de redução de jornada e salarial através de acordo individual.

Assim, de concreto, até agora, temos a destinação de R $\$ 51$ Bilhões para este Programa e, teoricamente, $\mathrm{R} \$ 98$ bilhões para o auxílio a desempregados e informais. Esse valor é absolutamente irrisório comparado ao volume de recursos destinados ao sistema financeiro pelo Banco Central: $\mathrm{R} \$ 1,2$ trilhões ${ }^{13}$. Não ouvimos o Ministro da Economia se lamuriar sobre a origem dos recursos para as instituições financeiras, que, até agora, aumentaram os juros e as exigências para fazer empréstimos para trabalhadores e empresas que necessitam de recursos para passar pela crise. Será que não deveríamos, diante de tal quadro, colocar em debate a nacionalização do sistema financeiro e de 
saúde privada, para além das medidas emergenciais de auxílio? Diante da brutal desigualdade de recursos, creio que a esquerda deveria ampliar o horizonte de luta política. Por aí seria um começo. sociedade minimamente civilizada, resiste a 44 mil pessoas mortas? Qual o cálculo político dos homens baixos em criticar, diariamente, o necessário isolamento, em postergar as medidas econômicas efetivas para salvar vidas e evitar o caos social? Ou, ao contrário, o governo dos homens baixos conta com o aumento da violência, dos saques, das rebeliões daqueles que, até agora, estão sendo abandonados? Será que o cálculo político é criar um cenário caótico, de saques, roubos, quebra-quebra, para tentar lançar uma última cartada? O cálculo é de manter uma base mínima de apoio, algo em torno de $10 \%$ a $20 \%$ do eleitorado, junto com as forças econômicas dominantes para lançar uma ofensiva fortemente autoritária? Ou não há cálculo algum e vivemos o puro e simples caos? Não acreditamos na segunda opção. A primeira, pode parecer improvável, mas nada impossível.

26 Tal questão nos coloca tarefas em curtíssimo, curto e médio prazos. Em curtíssimo prazo, temos que defender a ampliação irrestrita da rede de proteção social e auxílios para os trabalhadores ficarem em quarentena. Isso nos obriga a atacar, da forma mais violenta e radical possível, qualquer ideia ou reforma neoliberal proposta para conter a crise. Em curto prazo, infelizmente, não temos muitas saídas: no lugar do governo dos homens baixos, podemos esperar, no máximo, alguma alternativa de centro-esquerda que se sustenta na gestão mais ou menos humanitária do capitalismo, como foi o lulismo. A médio e longo prazos, necessitamos, urgentemente, alargar os horizontes históricos de ação política e retomar a ideia de que os trabalhadores podem autogerir suas vidas, em todos os planos. É necessário retomar um vocabulário político radical, para além da renda básica (uma ideia, no fundo, defendida por inúmeros liberais), para além do neokeynesianismo e afins. Não devemos ter como horizonte político rebaixado reviver o lulismo ou experiências neodesenvovimentistas. Poderíamos retomar, com conteúdo anticapitalista explícito, palavras como autonomia, autogestão, revolução e, por que não, socialismo. Creio que tais conteúdos, renovados de forma crítica, podem nos ajudar a produzir uma utopia que nos permita enfrentar a distopia contemporânea. O que não possível é passarmos por essa experiência para retornarmos para o mesmo mundo de antes. 


\section{NOTAS}

1. Alerta: todas as informações contidas no texto foram colhidas até o dia 3 de abril, data em que encerrei a redação do artigo.

2. E, devemos salientar, tal distopia não é um fenômeno brasileiro, é global. Ela vem sendo produzida desde a crise de 2008, tendo como alimento as consequências políticas, econômicas, culturais e subjetivas do neoliberalismo e os restos do nazi-fascismo, que, apesar de ter sido derrotado militarmente em 1945, nunca desapareceu completamente da tecitura do mundo contemporâneo. Sugerimos ao leitor o livro A Grande Regressão (GEISELBERG, Heinrich [org.], São Paulo: Estação Liberdade, 2019).

3. https://arte.folha.uol.com.br/equilibrioesaude/2020/evolucao-nos-casos-do-novocoronavirus/

4. https://www1.folha.uol.com.br/poder/2020/03/veja-o-que-bolsonaro-ja-fez-para-confrontarmedidas-de-combate-ao-coronavirus.shtml

5. "Eu estou com vontade, não sei se eu vou fazer, de baixar um decreto amanhã: toda e qualquer profissão legalmente existente ou aquela que é voltada para a informalidade, se for necessária para levar o sustento para os seus filhos, para levar leite para seus filhos, para levar arroz e feijão para casa, vai poder trabalhar".

6. https://economia.uol.com.br/noticias/redacao/2020/03/31/governo-nao-sabe-de-onde-sairadinheiro-para-pagar-r-600-diz-guedes.htm

7. https://www1.folha.uol.com.br/mercado/2020/04/motivo-para-inacao-do-governo-ebesteira-diz-maia.shtml

8. https://agora.folha.uol.com.br/grana/2020/03/informais-vao-receber-auxilio-emergencialde-r-600-a-partir-de-16-de-abril.shtml

9. http://www.planalto.gov.br/ccivil_03/_Ato2019-2022/2020/Mpv/mpv935.htm

10. http://www.in.gov.br/en/web/dou/-/medida-provisoria-n-936-de-1-de-abrilde-2020-250711934

11. https://www1.folha.uol.com.br/mercado/2020/04/veja-como-ficam-os-salarios-com-areducao-permitida-pelo-governo.shtml

12. https://g1.globo.com/economia/noticia/2020/04/02/como-ficam-os-salarios-com-a-reducaode-jornada-veja-simulacoes.ghtml

13. https://www1.folha.uol.com.br/mercado/2020/03/desafio-do-bc-e-fazer-r-12-tri-sair-dosbancos-para-empresas-e-familias.shtml

14. https://g1.globo.com/bemestar/coronavirus/noticia/2020/03/27/sem-isolamento-e-acoescontra-a-covid-19-brasil-pode-ter-ate-1-milhao-de-mortes-na-pandemia-diz-estudo.ghtml

\section{RESUMOS}

Este breve texto busca fazer um registro, em traços bem gerais, da forma como está sendo realizado o enfrentamento da pandemia do Covid-19 pelo Governo Federal. Em um quadro que caracterizamos como uma distopia política, econômica e cultural, que não se restringe ao Brasil, buscamos ressaltar algumas ações e imposturas que tornam o Governo Federal um dos maiores exemplos de incapacidade e incompetência para lidar com a crise atual. Diante de um quadro 
completamente inédito de isolamento social, peço desculpas ao leitor, editores e colegas por não conseguir produzir um artigo dentro dos cânones vigentes. Trata-se mais de um relato da angústia, minimamente organizado. Portanto, o leitor não encontrará citações e referências bibliográficas, mas apontamentos da pequenez e sordidez de quem nos governa.

Este breve texto busca registrar, en líneas muy generales, la forma en que el gobierno federal brasileño está abordando la pandemia de Covid-19. En un contexto que caracterizamos como una distopía política, económica y cultural, que no se limita a Brasil, buscamos resaltar algunas acciones e imposiciones que hacen del Gobierno Federal uno de los mejores ejemplos de incapacidad e incompetencia para enfrentar la crisis actual. Ante una imagen completamente nueva de aislamiento social, pido disculpas al lector, editores y colegas por no poder producir un artículo dentro de los cánones actuales. Es más una cuenta de la angustia, mínimamente organizada. Por lo tanto, el lector no encontrará citas y referencias bibliográficas, sino notas de la pequeñez y la miseria de quien nos gobiernan.

Caractérisé par un cadre de dystopie politique, économique et culturelle, le Gouvernement Fédérale Brésilien est si incapable qu'incompétent de gérer la crise de la Covid-19. Dans un contexte absolument inédit d'isolement social, je présent mes excuses aux lecteurs pour avoir écrit un récit de mon angoisse. Donc, il ne s'agit pas d'un article académique et orthodoxe, ce qui explique l'absence de citations et de références bibliographiques. Ce que j'ai voulu, c'était dénoncer la bassesse et la sordidité de celui qui nous gouverne.

From a political, economic and cultural cadre of dystopia around the world, I underline some actions and impostures that make the Brazilian Federal Government one of the most examples of incapacity and incompetence to dealing with the covid-19 pandemic. Facing a completely and unprecedented situation of confinement, I apologize to readers, editors, and colleagues for not being able to produce an article within the current academic canons but a distressed account slightly structured. There is no quotes nor bibliographical references but some notes about littleness and sordidness from our government.

\section{ÍNDICE}

Palabras claves: Distopía; aislamiento social; hombres de baja estatura moral; política sin escrúpulos; explotación del trabajo.

Palavras-chave: Distopia; isolamento social; homens de baixa estatura moral; política inescrupulosa; exploração do trabalho.

Mots-clés: Dystopie; isolement social; des hommes de faible stature morale; politique sans scrupules; exploitation du travail.

Keywords: Dystopia; social isolation; immoral men; unscrupulous politics; exploitation of work.

\section{AUTOR}

\section{GLAUCO BRUCE RODRIGUES}

Professor do Programa de Pós-Graduação em Geografia da Universidade Federal Fluminense Campos dos Goytacazes. Coordenador do Núcleo de Estudos sobre o Território e Conflitos Sociais. E-mail: glauco_bruce@id.uff.br 